\title{
The self and its causal powers between metaphysics and science
}

\author{
Rodolfo Giorgi ${ }^{1}$ • Andrea Lavazza ${ }^{2,3}$
}

Received: 30 November 2019 / Accepted: 18 September 2020 / Published online: 14 October 2020 (C) The Author(s) 2020

\begin{abstract}
According to the thesis of powerism, our world is pervaded by causal powers which are metaphysically basic. The aim of this paper is to defend the existence of the self, defined as a substantial entity, and its mental powers. This claim, which may seem a bold one, should not be deemed as inconsistent with scientific evidence. In fact, this approach does not ignore empirical knowledge, but is not bound only to it in order to understand entities, properties, and the relationship between them. Aristotelian powerism may show that the self, as the subject of one's mental acts, is a substance that has an essential nature. Firstly, we shall analyze the immediate evidence we have in support of the existence of the self as a substantial entity. We will show that the self is a substance because it possesses an essential character, i.e. an individual essence. We will take into account the Aristotelian perspective of substance, trying to show how the presence of a necessary property that makes every subject identical to itself and the phenomenal features of one's private experience point to the existence of a substantial entity that corresponds to the self. Secondly, we will try to justify the adoption of a metaphysical theory of causation based on powers, analyzing it in comparison with the main competing theories, namely hypotheticalism and nomism. Then, we shall proceed to show the causal properties of the substance in question, namely the mental powers. In fact, thirdly, we will embrace the thesis of powerism by defending the existence of a set of mental powers that should be attributed to the self. We will describe the main features of mental powers and we will show that they are conceivable as the pure intentional acts we perform by directing an intentional state towards an intentional object. In this way we show how a classic problem of philosophy of mind, relevant to science as well, can be addressed in an original way by a metaphysical approach involving powers.
\end{abstract}

Keywords Consciousness $\cdot$ Intentionality $\cdot$ Powerism $\cdot$ Mind $\cdot$ Kant

This article belongs to the Topical Collection on Powers in the world of science Guest Editors: Andrea Roselli, Anna Marmodoro

Andrea Lavazza

lavazza67@gmail.com

Extended author information available on the last page of the article 


\section{Introduction}

Scientific naturalism, namely the position according to which science is the most reliable kind of knowledge and the universe is constituted only by entities we can investigate via quantitative research, seems able to affirm itself as a general theoretical framework, based on the super-induction related to the practical success of science. However, from the standpoint of a more careful philosophical consideration, things are more complex. It is well known that scientific naturalism struggles to accommodate certain entities -such as the existence of the individual self and the causation determined by the self- into its ontology. Moreover, the very notions of self and its causation do not have a clear univocal description since different theories seek to account for them each with its own strengths and weaknesses. Choosing one theory of self-causation or another is not a philosophically neutral option but involves significant consequences in various areas of the ontology of scientific naturalism. In this paper we will try to move along this line, arguing in favor of the existence of the self as a substantial entity capable of powers and of a theory of causation known as "powerism", focused on the idea of the self's causal powers.

According to the thesis of powerism, our world is pervaded by causal powers which are metaphysically basic. This idea follows from the notion of causal powers that is rooted in the Aristotelian perspective. This perspective is still considered as philosophically sound and as a plausible approach at least in its major parts, since it provides a metaphysical explanation of the aspects of reality that are not easily accounted for by scientific naturalism. The Aristotelian account conceives of causal powers as the exhibition of two different categories of powers: an active causal power and a passive causal power. Active causal power refers to the substance's capacity of doing something, while the passive causal power is defined as a potential condition. ${ }^{1}$ The passivity of a substance is realized when a subject undergoes a change and receives a form. These two powers are instances of the same causal activity because they have identical duration. For instance, water boils when heated to $100{ }^{\circ} \mathrm{C}$ and this is the manifestation of fire's active power to heat and of water's passive power to boil under certain circumstances. This combination of active power and passive power is realized during the same fraction of time. However, in this respect, the realizations of active causal powers and passive causal powers do not refer to the same thing since they belong to two different substances.

The active powers should always be attributed to a substance defined as the agent, namely the subject who acts or determines a change, while the passive powers are the powers of the patient. In a metaphysical sense, the principle according to which the patient can undergo a change is the principle of passivity, namely the matter. The same substance might be agent and patient at the same time (for instance, $I$ can decide to voluntarily stab myself with a knife, and so I might be agent and patient at the same time) but necessarily under different respects: the active power should always be distinguished from the passive power. The aim of the present paper is to defend this framework, specifically focusing on

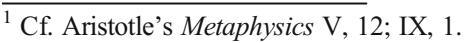


the notion of "powerism", which has recently been reevaluated. ${ }^{2}$ The Aristotelian perspective shows that our individual self, as the subject of our acts, is a substance that has an essential nature and is capable of powers. Our purpose is to show that the subject of consciousness possesses an essential character and can be conceived of as a substance in the Aristotelian sense, and that our capacity of instantiating thoughts as intentional acts is a manifestation of some mental powers.

In the second section, we shall discuss some relevant positions that show how consciousness plays a fundamental role in our mental domain and we shall analyze the arguments and the immediate experiences we have that support the existence of the self as a substantial entity. We will take into account the Aristotelian perspective of substance, trying to show how the logical analysis of our intentional propositions and the phenomenal aspects of one's private experience point to the existence of a substantial entity that corresponds to the self. We shall show that the intentional propositions that describe our mental states entail a specific property that qualifies every person in an Aristotelian sense. After showing the existence of a property that identifies us as substances, in the third section we will try to justify the adoption of a metaphysical theory of causation based on powers, analyzing it in comparison with the main competing theories, namely hypotheticalism and nomism. Then, we shall individuate the causal properties of the self as a substantial entity, namely the causal powers. In fact, in the fourth section we will embrace the thesis of powerism by defending the existence of a set of mental powers that should be attributed to the self.

\section{The essence of the self}

\subsection{The fundamental role of consciousness}

Some philosophers argue that there is no such thing as the self in the natural world. What we define "self", for them, is just the product of our creativity, namely a fictitious construction created by our minds, but there is no substantial reality that corresponds to it. Most materialist perspectives deny the ontological existence of the self as an entity independent from the physical states and as an essential thing that interacts in some way with the brain. The empiricist tradition refuted the metaphysical notion of substance by arguing that only specific instantiations of our sense perceptions provide an authentic knowledge of the world and that the reality of the substance per se is unknowable. Some philosophical and psychological theories maintain that we are able to integrate our everyday experiences into a sort of narrative self that determines the sense of unity and personal identity which is peculiar of human interior mental life (Kind 2015).

This kind of self has to be primarily conceived in a functional sense and not in an ontological one. Moreover, reductive physicalism and the empirical sciences argue that

\footnotetext{
2Marmodoro (2007), (2009), (2010) and Mumford and Anjum (2011) defend an Aristotelian perspective that describes causation as the manifestation of a link between active causal powers and passive causal powers. Moreover, Christopher and Marmodoro (2017) argue that the organisms' capacity to persist over time derives from a structural power that causally determines a specific series of structurally adaptive morphologies. This means that it is plausible to defend an Aristotelian view of powers even when investigating the biological structures of the natural world.
} 
all the individuals that exist in the physical world are physical objects. ${ }^{3}$ Physicalism maintains that our knowledge of things depends on empirical data and these data constitute the ultimate limit of what we can say about any actual non-abstract object in the world. According to Dennett (1991), for instance, the notion of self is an illusion: we believe we have something like the "self", but this self doesn't actually exist. In this way, a major part of reductive physicalism, called eliminativism, denies the truth of our interior self-consciousness. However, in the contemporary debate in the philosophy of mind, some of the most recent theories about consciousness take into account the phenomenological aspects of the mental domain and do not limit their analysis to the empirical data. ${ }^{4}$

Mental aspects, like the subjective faculty of "attention", the introspective access of consciousness and so on are useful in order to describe the states of consciousness that can't be translated or codified by the vocabulary of micro-physics. Moreover, we can acquire knowledge of mental activity and its correlation with neuronal and brain activity only if we make reference to those immediate phenomenological data we find in consciousness, which allow us to identify the mental elements we are taking into account when we try to reduce the mental to the physical. An interesting hypothesis was proposed by Tononi with his theory of consciousness, called Integrated Information Theory (IIT). Tononi (Tononi and Koch 2015; Tononi et al. 2016; Koch et al. 2016) claims that consciousness exists, and this is a fact that cannot be further broken down. In Tononi's words, "that my experience here and now exists is the only fact I can be sure of immediately and absolutely. Moreover, my experience exists from its own intrinsic perspective, independent of external observers". Moreover, consciousness is structured, meaning that it is composed of multiple phenomenological distinctions (objects, colors, shapes, body states...); it is specific and informative for the subject. Given these essential properties that can be found in all experiences, there must be reasons why those properties are what they are. The IIT postulates that, for each essential property of experience, there is a causal property of a physical substrate that accounts for it.

To simplify, the phenomenal axioms give rise to postulates on the properties of the brain mechanisms that support consciousness. These axioms are: (i) conscious experience is informative (each conscious experience differs in its specificity from countless other possible experiences); (ii) conscious experience is integrated (conscious experiences cannot be divided into parts). It follows that a system has subjective experience to the extent that it is able to integrate information. This capacity depends on an optimal balance between differentiation (information) and unity (integration), which is a nontrivial condition for a physical system. Indeed, at first sight, it would seem like these two properties are extremely difficult to reconcile.

All that said, it seems that a fundamental fact about intentionality is that "we", as subjects of mental acts, are always connected to intentional acts within our mind. Intentionality is rooted within our consciousness, because every time we direct a mental state $x$ towards an intentional object $y$ we are always conscious of intrinsic properties independently from the external things. Some intentional processes are mental processes because the subject of consciousness is the thing that is actually aware of the

\footnotetext{
${ }^{3}$ For reductive physicalism, cf. Churchland (1981) and Dennett (1971), (1987).

${ }^{4}$ For example, Baars (2006); Crick and Koch (2003), (2005); Graziano (2013); Tononi (2008).
} 
psychological state, the thing that instantiates that state and the thing that directs that state towards an intentional object. If a subject believes something, he has a peculiar access to the knowledge of the content of that mental state. This knowledge is obtained when he is directing a mental state to an intentional object and he is aware of that intentional object at a particular time. This whole process seems to happen within our interiority. So, intentionality is not a matter of language because our mental states are described by propositions that appear to be certain in virtue of some interior conditions.

In this vein, it can be claimed that intentional states which have a phenomenal character are the only states that are, as Horgan and Kriegel (2008) argue, "uncontroversially, unquestionably, prototypically mental". Other mental states can count as mental only when they have the right relationship to phenomenally intentional states. Accordingly, "phenomenally intentional states are the only ones that qualify as mental in and of themselves and regardless of any relationship they might bear to any other state, or indeed anything else whatsoever" (Ibid.). A reason for that is those states have a first-person access which does not need a theoretical understanding. In addition, phenomenally conscious states can be taken to have intentionality based on the transparency of experience (Harman 1990). And following Kriegel, one can maintain that since mental images and occurrent thoughts are the most central and distinctive features of mind and they are phenomenally intentional states, it implies that phenomenally intentional states are paradigmatically mental.

As I instantiate thoughts that can be accessible only in the private dimension of my mind, my intentional propositions are just tools that I use to describe something I have in my mind. Consequently, this entails that the intentionality of propositions depends on the intentionality of thoughts. My capacity to direct a thought to an intentional object is what justifies a certain proposition: the very fact that I'm instantiating a thought is the fact described by the proposition I intentionally decide to use. In this sense, mental states intentionally precede intentional propositions.

\subsection{Evident intentional propositions}

In our view, one can analyze the notion of self based on the consideration of the mental terms and the propositions we intentionally use, which intuitively appear self-evident and justified. There are propositions about the intimate nature of the mental domain which are evident prima facie, i.e. in the sense that we have strong intuitive reasons to accept them. However, this is not to say that we dismiss any empirical knowledge or study of the brain's activity or reject the empirical data provided by neurosciences.

If my propositions which describe my intentional acts are evident to me, then they entail the existence of a particular entity. We need to take seriously the ontological commitment of names and singular terms referring to subjects of intentional propositions. The case exemplified by singular terms that are subjects of intentional propositions is specific and different from other kinds of propositions. In order to have knowledge of the intentional objects instantiated by the thoughts of any individual, we need to admit that singular terms included in intentional propositions are committed to the existence of some sort of things. The subject who intentionally uses a proposition exists as an $x$ that possesses the property as is represented by that proposition. If we refuse this thesis, we will risk facing the impossibility of deriving any ontological consequence from the intentional propositions. For this reason, we have decided to 
analyze the singular terms of the propositions that describe the intentional acts of a subject with a de re modality.

The first step is to focus on the propositions that describe the mental acts or mental experiences we are instantiating. Accordingly, we selected propositions which are evident and certain, because they are describing conscious states that are experienced by the subjects. The second step is to evaluate the ontological consequences of the evident propositions regarding the mind. It is also useful to say that we are not considering propositions that describe mental events from a third person perspective but only the intentional propositions that each one of us uses to describe their mental states, namely their beliefs, thoughts or feelings. In fact, we argue that when we think of ourselves as subjects, we realize that we immediately know some propositions that presuppose the existence of what we call "I". There are some propositions regarding the subject that appear immediately evident prima facie. Let's consider the following propositions as uttered by me:

P1: I'm thinking that my cousin's car is an SUV.

P2: I'm feeling joyful.

I may state that these propositions are evident to me because I know them in a direct and immediate way. I may also consider P1 and P2 as two propositions that describe my mental states, and, provided I'm not lying about the instantiation of my mental states, they appear certain to me because they are justified by some conscious states that I instantiate at a particular instant $t$. This means that the basis for the knowledge of P1 and P2 is something I'm aware of internally, and these conscious states provide a justification for my intentional propositions. So, we are not considering P1 and P2 as two propositions that can be judged on the basis of their truth value but as two intentional propositions which describe the thoughts or feelings instantiated by the subject who utters these propositions. If I have some conscious states which constitute the conditions of the justification of these two propositions, I can believe in P1 and P2 and consider these as evident to me even though they don't actually describe something which is true.

Suppose that my cousin's car is a Station Wagon but I believe that it is an SUV, maybe simply because I'm not familiar with certain kinds of vehicles and I'm not able to recognize the distinction between the two kinds of cars. My belief is false, but I believe it is true in virtue of the justification provided by a mental state that I can have at an instant $t$. However, after having acquired new data about the distinction between an SUV and a Station Wagon, or maybe after my cousin explained to me the features of his car, I could have a new mental state that will be directed towards a new intentional object, namely the fact that my cousin's car is a Station Wagon and not an SUV. Of course, if I know the distinction I can apprehend the difference between an SUV and a Station Wagon; in this way, I will adjust my belief and form a new belief that is going to be correct and adherent to reality. However, at a particular instant $t$, when I instantiate the thought described by the proposition 'I'm thinking that my cousin's car is an SUV", P1 looks evident to me because it is supported by the internal condition constituted by the conscious state of which I am the subject.

We have already assumed that linguistic intentionality is a manifestation of mental intentionality, so when I use P1 I'm an entity who has introspective access to the 
intentional object described by P1. If I direct my thought towards this intentional object, I can grasp the intrinsic property which qualifies the mental state that I instantiate when I use P1. This property is only accessible to me, not to another individual, and so it will be present and certain for me when I instantiate this thought. The fact that I can have access to an intrinsic property which belongs to that mental state implies that P1 appears justified and consequently evident to me. It seems, in this way, that the conditions of justification of my intentional propositions are not external objects, because we often possess some beliefs that appear evident to us independently from external reality. Hence, intentional propositions are evident and certain for a subject at a particular time and not depend on any external condition, because I'll be able to hold a new belief in the future that will be different from the current ones.

As regards the analysis of $\mathrm{P} 2$, it is possible that I can have only an impression of feeling joyful. As a matter of fact, my friends or my family could know my feelings better than me and sometimes they might think that I am apparently joyful but not really joyful. I sometimes could only feel joyful on the surface while being actually stressed or concerned because of something disgraceful that recently happened to me. However, even though I don't appear totally joyful to others or fail to define my feelings correctly, I'm always able to immediately recognize that I'm the subject of that particular conscious state at that particular instant $t$. I could fail to explain my feelings, or struggle to recognize that I'm not completely joyful, but it would be odd to say that I don't recognize that the feeling of the conscious state described by P2 is mine. I'm still a subject that feels something and I'm the subject of a mental state that, of course, is my mental state, even though I'm not able to explain it correctly and I think that it is a state of joyfulness instead of a state of a different feeling. So, it seems that there exists a what it is like to be the subject of a particular mental state that is only accessible to me and precluded from others.

Now, one might ask: what are these epistemic facts which make P1 and P2 so evident to me despite the external facts that could make these two propositions false or inaccurate? First of all, we have already claimed that there is an intrinsic characteristic of our conscious states every time we are conscious of a certain mental state. We are able to know that a mental state is a mental state of ours own since we have introspective access to it. Every thought or feeling is possessed in a subjective way by an agent, and this is not explicable on the basis of extrinsic elements. This entails that every conscious state I instantiate at an instant $t$ is immediately my conscious state, it belongs to me and not to everyone else. I can fail to define or recognize the name of a conscious state extrinsically (for instance by misrepresenting its nature) or I can hold a belief that is not actually true, but I will be always sure, now and in the future, that even though the evident propositions I intentionally use are not true, the conscious states which justify them are my conscious states because I have direct access to them.

Once I have direct, introspective access to my conscious states, I know their intrinsic properties and this knowledge can't be shared by any other individual. Consider a specific mental state $x$ that I instantiate at an instant $t$ and that is consciously possessed by me by having access to its intrinsic property: is there a possible world where that exact mental state is possessed by me and at a same time possessed by any other individual? It seems not to be the case, otherwise the mental state in question could not be that specific mental state $x$ that I instantiate at an instant $t$ by having access to its intrinsic property. As a matter of fact, I can certainly believe in an intentional statement 
which is false (and other individuals could plainly know that it is false) but it's always only me who has direct access to the mental state described (whereas other individuals necessarily don't). So, we can develop a principle of justification of our intentional propositions in the following form:

for every $\mathrm{x}$, if $\mathrm{x}$ is an intentional proposition I use and that appears evident to me, $\mathrm{x}$ is justified by an internal condition constituted by an actual conscious state that I instantiate at an instant t. ${ }^{5}$

Even though I actually fail to recognize that P1 is false, or I'm not able to correctly explain the nature of the phenomenal state described by P2, I always have the consciousness of something in both cases, namely I'm always the subject of a private conscious state that occurs at an instant $t$ and to which I have direct and introspective access. My conscious states represent the epistemic conditions of justification of the propositions that I intentionally use to describe something. And it is exactly based on these evident intentional propositions that we are going to define the subject as a substance. ${ }^{6}$ This claim, which may appear bold today, should not be immediately opposed with scientific evidence. In fact, this approach is philosophical rather than scientific: it does not ignore empirical knowledge but is not bound to it in order to understand entities, properties, and the relationship between them.

First of all, we may assume that a substance is an entity which is necessarily identical to itself. A more precise definition could be the following:

for every $\mathrm{x}, \mathrm{x}$ is a substantial entity or a substance if $\mathrm{x}$ possesses a fundamental character that cannot be removed or modified without deleting that entity.

In this sense, every subject of consciousness is to be considered as a substance if it is qualified by an essential property. Every time $I$ intentionally utter a proposition that describes an intentional act which I'm going to perform, $I$ am the only entity who instantiates the conscious state described by this proposition and $I$ am the only entity who has direct and introspective access to that conscious state.

The internal justification of a proposition describing intentional acts, as intentionally used or uttered by a particular person, depends on the existence of that particular entity. This means that this entity is defined by a property which pertains uniquely to that individual and not to a different one. Consequently, each of us is characterized as a person by an essential property that specifies the nature of every individual. In other words, I have a property that identifies me as necessarily possessing a specific nature that defines my essence. This property is uniquely owned by me and no other individual possesses this property, but every individual has their own property or individual essence. Thus, each self is an individual entity distinct from all others by

\footnotetext{
${ }^{5}$ A limitation to this principle is that it should apply to rational agents who can build their system of ordinary beliefs about the world and who are cooperative with other individuals to prove if their beliefs are true or not. This principle should not be applied to any individual who is affected by a psychiatric pathology and who is not willing to interact or cooperate with their community in order to change their beliefs once they realizes that they are wrong or totally absurd.

${ }^{6}$ Cf. Chisholm (1976), (1989) on the idea of a substance that corresponds to the self.
} 
virtue of a specific nature which is specified by a property that characterizes its own essence.

As the evident character of my intentional propositions depends on the existence of an essential thing, there must be a subject of the acts described by my intentional propositions that exists as an essential thing and that is qualified and individuated by a necessary property. This necessary property that qualifies each subject or self as that subject or self is the individual essence. So, the propositions that describe our intentional acts always presuppose the self and entail the existence of the individual essence. In order to intentionally use the propositions that describe the intentional acts there must be a subject that owns an individual essence. This subject (I) is a substantial entity since it is presupposed by all the evident propositions about mental activity and intentional acts used by me in an intentional way. In fact, all the singular terms of the propositions that describe the intentional acts and the mental terms should be analyzed through a de re modality.

This modality reveals that the subject of the propositions, as used by me through the singular term "I", refers rigidly to the same entity in every possible world. When we actually and intentionally use the singular term "I", we refer to an individual entity that has a constant nature. Every time I use the singular term "I", then, I necessarily refer to the same reality. This happens because the entity that the singular term "I" refers to always has characteristics that cannot be removed or modified without thereby deleting that entity. If we indeed removed or modified a part of the features that characterize the subject as a substantial entity and that therefore exist as necessarily anchored to the object identified by the singular term "I", we would never refer to the same subject every time that we use the singular term "I" in an actual and intentional way.

In order to further explain this thesis, we can imagine the following situation: let's suppose that I am an artificial structure that has acquired a consciousness and that is intuitively aware of being an existing entity. I have suddenly developed this form of rudimentary consciousness based on the sophisticated physical mechanisms designed by the engineers who have designed and built me. Let's suppose that, since I have developed a form of consciousness, I'm able to carry out and produce activities and mental states of a functional nature, in a totally independent and unpredictable way (similarly to the mental states of human beings). If I know that I am something and at the same time I produce some mental states and events, ${ }^{7}$ I also have a mental state equivalent to the proposition "I exist" that I intentionally use to actually refer to myself as an existing entity.

But what kind of ontological entity does the mental state I'm thinking about refer to? It certainly doesn't refer to the physical entity that constitutes me at the ontological level (that is the artificial structure). If that was the case, I couldn't be the sole subject of my consciousness because my structure is a physical one, certainly divisible into simpler parts: therefore there wouldn't be that element of absolute unity that distinguishes and characterizes the self as the unique center to which the mental activities produced by that subject belong. So, my mental state equivalent to the proposition "I exist" will be referred to a substantial entity somehow connected to the physical

\footnotetext{
${ }^{7}$ Mental events may be defined as the passing from one mental event to another. Also, I produce a mental event, instantiating a new mental state, when I wake up in the morning after a deep sleep.
} 
artificial structure, just as the substantial entities of human beings are causally connected to their brains. ${ }^{8}$

Therefore, in any case, if the self, considered as a substantial entity, was connected to any artificial structure it would necessarily be a simple and indivisible entity connected to that structure, by virtue of the fact that any subject of consciousness, as it exists and is aware of its existence, can only be individuated because of its individual essence. ${ }^{9}$

Thus, the main aspects of the individual essence of the self, conceived as the necessary property that qualifies every self or subject of consciousness as such, are the following:

- The aspect of unity, which makes the self a substantial entity characterized by a fundamental character that cannot be removed or modified without deleting that entity.

- The aspect of indivisibility, which makes the self qualitatively different from every physical entity or artificial structure.

- The aspect of simplicity, which makes the self always presupposed in its entirety by every true proposition intentionally conveyed by a person at a time $t$ and describing their intentional act. $^{10}$

A fundamental distinction between our subjective perception of the self as a substantial entity and our perception of physical entities is that the substantial entity cannot be analyzed through a predication that defines it extrinsically, that is, by examining its relationship with some properties or entities that are different from it. It can only be described and defined as an entity in itself which means that we immediately and directly know that it exists in a constant way, and it is necessarily identical to itself. Therefore, the "I" as a subject of our mental events is immediately grasped as an entity characterized by its essential reality. ${ }^{11}$ We wouldn't be able, indeed, to grasp or know

\footnotetext{
${ }^{8}$ One might wonder if the conscious machine develops a "new" self every time it instantiates a mental state equivalent to the proposition "I exist". It would be challenging to investigate what kind of personal identity is possessed by this "artificial" self and if there is a sort of causal continuity between its previous states and the next states. However, the problem is that we are not able to know "what it would be like" to be a self emerging from a machine. It is certainly impossible to know if the self of this machine has the same psychological continuity that characterizes the human self or if it just pops up randomly every time the machine produces a certain activity. We are in the field of possibilities and the only actual existent self we can analyze is the human one. Here we contend that any kind of self-consciousness that might emerge in nature will have a substantial entity as the object of itself and will not be identical to any physical structure because to say the opposite is contradictory.

${ }^{9}$ In short, the idea of this thought experiment is the following: if some artificial structure ever develops a sort of "self", this self won't be any different from the "self" we possess as human beings. Consequently, it will be an essential entity connected to its artificial structure, in the same way as we human beings are connected to our brains. In other words, it is in principle illogical to contend that a new "self" or consciousness might emerge from a machine and be totally reducible or identical to a physical structure; if this happened, this self would be de facto a new essential entity which interacts with a hardware, just as we interact with the brain. Therefore, it would not be a physical entity in a strict sense. In fact, whatever self that is similar to the human self is necessarily an essential entity. Ultimately, either a self cannot emerge from a machine or, if it ever did, it would be an entity non-identical to its physical structure.

${ }^{10}$ Once we have shown the existence of the self as a substance, it will be possible to derive the causal powers from this substance.

${ }^{11}$ For the debate on personal identity, cf. Parfit (1984) and Shoemaker and Swinburne (1984).
} 
only a part of this subject: that would be impossible. Because I know that the mental states that I experience are my own mental states, then the "I" associated to those mental states and thoughts refers to a simple thing. If it referred to a composed thing, I could not have the direct knowledge that those mental states and thoughts are my mental states and thoughts. We are therefore able to grasp the subject in its entirety. I cannot immediately grasp myself as only a part of the subject and consequently believe that my mental states are associated to that part. As it is impossible to perceive the self as a composed entity, without the main aspects of the individual essence we have described above, the self exists as a thing in itself. The reality of the subject cannot be defined in connection with any other reality different and independent from the subject itself. Therefore, the self exists as a simple thing and as a thing in itself because there is a fundamental unity that characterizes all the intentional acts described by our intentional propositions which always refer to the same entity in its entirety, not in a partial way or directed to the simpler parts of a composed entity. We can't help but refer to the same thing every time we perform an intentional act, or we intentionally convey the singular term "I".

\subsection{A Kantian-like critique and interpretation}

One of the most notable arguments against this view is the one proposed by Immanuel Kant in the Critique of Pure Reason. ${ }^{12}$ According to Kant, it is not possible to have direct knowledge of the self because the subject of our thoughts is unknowable, namely we can't know it as a thing in itself. The "I", as the singular term we use to refer to the subject of mental states, doesn't refer to any substantial entity, it is only a formal unity. The mistake of ancient metaphysics, according to Kant, lies in the controversial attribution to the term "I" of a set of positive values, including the idea of an individual entity. Therefore, the self represents the supreme formal condition of any mental activity but it is not a substance or a unified individual entity to which we can apply the categories of traditional metaphysics. Here we don't have the ambition to try to counter the Kantian position, or to give new interpretations of it; rather we aim to show some consequences that follow for the analysis of intentional propositions if we accept the Kantian perspective on substance.

It may be worth noting that some recent interpretations of the entire Kantian corpus go in a different direction. Specifically, Wuerth (2014) claims that, against traditional empiricist approaches, Kant argues that we are conscious of our own noumenal substantiality and simplicity. Wuerth maintains that Kant's authentic interpretation can allow us to say that "we are aware, through pure self-consciousness, that we are a something in general, that as such we have powers through which we can bring about accidents (mental states, in our case), but that we are distinct from all accidents and so all predicates, so that we can draw no determined or useful conclusions about ourselves" (Wuerth 2014: 117).

The idea is that "essentially, in transcendental idealism, we can, noumenally, say of ourselves that we are substances, but (because we encounter ourselves not as object but as subject and are thus distanced from our accidents as objects) draw from that fact only

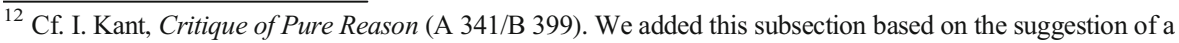
reviewer.
} 
that we are 'something in general', not further claims related to immortality" (Ibid.:185). And, consequently, according to Kant interpreted in this way "our substantial soul is simple in that, in itself (...) it is a single thing, a unity, without spatial or temporal complexity (Ibid.: 185-186). Obviously, this interpretation of Kant has not yet become mainstream, and therefore it is necessary, albeit briefly, to consider the objection to our position that comes from the classic interpretation of the Kantian Critique.

If Kant is correct, I must conclude that every time I make any assertion about my feelings or beliefs, the singular term I use to indicate myself is just an empty box or a functional term. In other words, the singular term "I" doesn't refer to anything that exists as an entity. The consequence, in this case, would be the following: if the term doesn't refer to an entity who can be the subject of predicates, there is no subject of the states described by the intentional propositions. At this stage, the problem is that we couldn't ascribe any epistemic value to our intentional propositions if there were no subject for any predicate that manifests mental acts. In fact, how would it be possible for one to explain, describe or make any assertion about their feelings or beliefs if there were no entity who perceives or believes those states?

Let's consider again P1: could we really see the "I" in P1 as a functional term if I intentionally utter P1? The only way to attribute any sense to this intentional proposition is to admit that the singular term "I" is the subject of P1. But what kind of subject could it really be? To what kind of thing does it refer? Maybe we could try to conceive this thing as a property or a state of affairs. However, this is not an easy task as it must be a thing to which we can attribute the predicate described by P1. It must be the bearer of this predicate. Then, we can also suppose that it is a sort of fictional thing or an indefinite object; in other words, the singular term "I" in P1 doesn't refer to anything. But this would entail that when I intentionally utter P1 I don't actually exist (and this doesn't seem to be the case). Therefore, if I can't conceive that the singular term "I" in $\mathrm{P} 1$ refers to nothing, the upshot is to admit that the singular term "I" in P1, as intentionally used by me, refers to an existing entity, namely an entity which can possess some properties and be the bearer of some predicates. This kind of entity must be a definite object, a something that exists and to which the predicates described by my intentional propositions belong to. In this case, the "I" in P1 is not just a formal unity.

\subsection{The intuition of the self}

So far, we have developed a method for the individuation of the self which is based on an epistemic argument: every subject is able to recognize that there are evident propositions which describe their mental states. These propositions are evident because every subject knows directly that these states belong uniquely to them, and that they are justified by internal conditions as the conscious states that the subject instantiates. These propositions describe one's mental states and presuppose the existence of an individual entity identical to oneself. That entity is consequently defined by a necessary property, i. e. the individual essence. Thus, the individual essence is implied by the evident propositions that each of us use to refer to mental states that are possessed uniquely by us.

Now, let's examine the phenomenal fact that regards our immediate and intuitive awareness of being an entity. As regards our intuition of being an entity, we 
immediately know an evident truth which allows us to recognize the entity that we define "I". Our awareness of being something, or rather of existing as an entity that can be defined as a subject which is the core of our experiences and thoughts, is determined by the intuitive certainty of being an individual or a person. If indeed the subject, that is, the entity normally called "I", had no these intuitions, we wouldn't be able to connect our conscious mental states and events to a center representing the cornerstone of our consciousness. ${ }^{13}$ In that case, we would be the passive audience of an uncoordinated stream of mental events that we would never be able to define as our own mental events.

In other words, the fact that I am able to define the mental events that I think and experience as the mental events which belong to me and that are part of my biography of mental events depends on the pre-theoretical and pre-conceptual intuition of a center which those mental events refer to, as they are owned by that center. Intuitively grasping the "I" in a pre-theoretical way means perceiving the subject of the mental events. One may object, as Hume did, that we are not aware of any one single entity as the "self" but that we only ever experience a bundle of perceptions that appear in our consciousness as in a sort of theater. This is the tenet of the so-called bundle theory. A possible response is that the very entity who investigates the nature of this bundle of perceptions is the same entity whose existence is ruled out by the defenders of the bundle theory. If I try to defend the bundle theory by saying that I'm only ever aware of a flow of impressions without there being a single subject, I'm also implicitly recognizing that those impressions belong to $m e$ and this means that they are $m y$ impressions. So there must be an evident inner awareness of a single subject grasped as a substantial entity.

This kind of evidence is a pre-analytical knowledge, which means that it is not the result of an inference or of a deductive demonstration. It can be described as direct knowledge that allows us to know a certain object in a total way. We cannot only have a partial perception of the self: every time we know our selves we grasp them as objects in their entirety, so these entities are completely and totally owned by our consciousness. We are not trying to deny that we are often unaware of the totality of the psychological causes of our actions or of the totality of our psychological characteristics. For instance, I could have difficulties in admitting (or simply not be fully aware) that sometimes I show some aspects of greed, and my friends might be more aware than me of this attitude. Even though I actually instantiate a particular mental state at a time $\mathrm{t}$, it is also possible that I fail to recognize what kind of specific mental state it is, as we have seen earlier by analyzing the case described in P2. It might be also the case that I resist to attribute to myself a psychological aspect I don't want to accept. However, we are not contending that self-consciousness determines total knowledge of the traits of our personality. We are considering the perception of the self as the perception of being something, namely a thing we know directly as the subject of all our mental events. Despite the fact that I'm not able to attribute the correct name to a mental state or I don't describe it properly, as mentioned, there exists a what it's like to be the subject of a particular conscious state that is only accessible to me and precluded from others.

\footnotetext{
${ }^{13}$ For instance, Meixner (2004) suggested that the self can be considered as the center of the subjective experience and that when I intentionally use the singular term "I" I always refer to that center.
} 
Every time we express or reveal our individual connection to a mental state, we indeed constantly assume the existence of the subject. Therefore, we don't need to infer the existence of the "I" from any other concept or fact: it is grasped in a pre-analytical way, and this intuition allows me to attribute my mental events to myself. It is therefore thanks to an intuitive evidence connected to the existence of the "I" that we can clearly establish that every mental event we instantiate is a mental event of ours own. One could hypothesize that every single mental event constitutes a distinguishable and identifiable self, but there exists a degree of continuity between the various instances of mental events. This continuity is due to both the causal connection and the similarity of conscious content, as happens for our autobiographical memory.

However, Carruthers (2017), for example, argues that every person interprets their own mental states in the same way as they interpret the others' mental states and that we are not directly aware of our intentional states. We can consciously use our inner speech and our own visual imagery as part of an interpretative process in which most of the inferences we make are hidden and not accessible to us. These inferences belong to an unconscious process ongoing in the mind. According to Carruthers, the supposed transparency of mind and the introspective access of consciousness have only a heuristic and functional value in order to facilitate human communication and interactions. Indeed, we can easily admit that we don't have a direct awareness of many of the processes and the inferences that constitute the functioning of our minds. Nevertheless, even if there are functions of our mental activity that are unconscious, most of our mental states are always accessible by introspection and our internal awareness reveals the presence of the self. The fact that sometimes we cannot be aware of some states of our personality or of some functions of the mental domain doesn't rule out that most of the time, when we are thinking of something, we immediately have an intuition of being the subject of that mental act.

It is known that the concept of intuition can be problematic. In this case, we can resort more specifically to the idea that when we are thinking about something, this mental act has an what-it-is-like effect on us that can be analytically distinct, something we cannot easily get rid of. Even trying to do a thought self-experiment, it seems difficult to be able to observe free thoughts, completely detached from us, or to be just that thought without anything else connected to it. The deep meditation that sometimes seems to lead to the result of being totally immersed in a thought to the point of making everything else disappear (assuming it makes philosophical sense to express this way) implies as its premise that the I make an effort to "disappear". In other words, it is the subject who is part of and then returns to the mental theatre.

The very fact that I'm able to recognize that I'm a simple and essential entity and that I have an immediate intuition of being a single thing is the necessary precondition to search for and analyze all the unconscious processes from the third person perspective. Therefore, the knowledge of the self appears to be an immediate and internal awareness that grasps the very essence of the "I". The evidence we are referring to is defined internal self-consciousness: it takes shape when we become perfectly aware that the mental states that we instantiate, and experience always belong to the entity that we call "I". Self-consciousness is therefore a kind of intuitive awareness, it is immediate and direct, involving every mental event. Thanks to the immediate and evident nature of this phenomenological knowledge, we are able to outline the substantial reality of the subject of the mental states. 


\section{Causation and powers}

Powers are shaped by dispositional (as opposed to categorical) properties, such as fragility. For example, a cup might be fragile, but this doesn't mean that it will be broken. A dispositional property refers only to the possible behavior or manifestation of an entity, not to its actual state. We can't directly perceive the dispositions of an object, because they are not measurable or quantifiable like the categorical properties. For a long time, powers have been considered real; then, the empiricist tradition inaugurated by Hume denied that powers can be traced back to some "original impression", that is, to the criterion linked to directly observable "sensible qualities" that can be individuated through an empirical method. Today, the problems which have been stressed in relation to alternative theories allow us to formulate an updated theory of powers.

Firstly, we must differentiate between powers and properties which are not powers. According to Molnar (2003: 57), powers have two specific characteristics. In the first place, a power must have directionality: it must be oriented towards some result. Directionality thus allows for a first distinction between powers and non-powers. The second characteristic is that powers can be ontologically independent of their manifestations. Powers can exist even if they are not, have never been and never will be, exercised. Evidently, though, these criteria are not conclusive, because the idea of directionality is not so clear in all circumstances, and can lead to a great variety of dispositional predicates in which it may be difficult to distinguish a homogeneous class of properties that corresponds to them. A further criterion is the modal one: a property such as fragility refers to a certain effect, i.e. breaking, so if an object is fragile, it can or could break under certain conditions. If this were not true and no similar conditions were given, it should be concluded that the object is not fragile. So, an entity can have a power only if it can or could manifest it under certain conditions, determined by the type of power in question.

For one to state that powers are genuine and irreducible properties, one needs to first consider objections and alternatives. This claim is postulated by the Dual Aspect Theory, ${ }^{14}$ according to which attributions of causal powers are fundamental. In this view, properties are not identified by their temporal or spatial locations, but by their causal powers. Fundamental properties necessarily have causal powers which constitute the necessary conditions to identify properties. According to this thesis, the causality of the properties is such by virtue of their causal powers. Just as sound properties can be identified by pitch, intensity, timbre, and duration, so there can be causal aspects of properties. In this sense, one power of water it is to extinguish flames, but not to make a sheet of paper rigid. The Dual Aspect Theory also says that properties can have more aspects other than the causal functions that characterize them: causal aspects are not the only ones that identify a property. In fact, properties may have the same causal profile but have a different haecceity ${ }^{15}$ distinguishing them (Martin 1994). Furthermore, the Dual Aspect Theory states that causal properties are necessary: they are something that an entity has as a matter of necessity and they belong necessarily to an entity. For

\footnotetext{
14 The Dual Aspect Theory defends the idea that the mental and the material are different aspects or attributes of the same reality, which itself is neither mental nor material. This theory is usually historically attributed to Spinoza (1677).

${ }^{15}$ We can define "haecceity" as the property of a thing in the light of which "that" thing is unique.
} 
instance, the power of water to extinguish flames is something that the property of being water must have. The Dual Aspect Theory therefore affirms that fundamental properties are those that have their causal powers necessarily and are not identified only by their causal aspects (Koons and Pickavance 2015, 2017).

In the light of the above, the causal powers theory seems better grounded than rival theories, such as Hypotheticalism (or Neo-Humeanism) and Nomism (Boyd 2011). Let's see why. These views state that causal properties are hypothetical facts or scientific laws, as opposed to causal powers. Powerism argues instead that hypothetical facts or scientific laws can be reduced to causal powers, since powers can in principle ground the existence of other entities. Consider why fire melts ice. Powerism states that there is a fundamental dispositional property of fire that allows it to melt ice under appropriate conditions. Hypotheticalism postulates hypothetical truths instead and wants to reduce causal properties to hypothetical facts. In this perspective, it is stated that the power of fire to melt ice is grounded in the fact that, if you place ice near fire, then ice melts. Supporters of hypotheticalism believe that there is no power beyond the hypothetical facts that establish the truth of counterfactual assertions. Hypothetical truth makers are hypothetical facts and explain the difference of meaning in different counterfactuals.

Another way to express this position is to consider a conditional analysis of dispositions and powers, one that reduces them to categorical properties. This would exclude the need to extend our ontology to powers, as exemplified by Ryle (1949: 43). According to him, having a dispositional property is not the same as being in a specific state or undergoing a particular change: it rather means being inclined to be in a particular state or to undergo a particular change under a given condition. This conditional analysis of powers basically says that something is inclined to give a certain response to a certain stimulus, at time $t$, if and only if it receives that stimulus at time t. In that case, it will give that certain answer. However, there are ingenious counterexamples that seem to falsify this conditional analysis of powers. ${ }^{16}$

Specifically, Martin (1994), using finks and masks, has devised some thought experiments challenging any position that considers counterfactual truths as fundamental. For example, it may be thought that a metal cable has the property of conducting electric current. The attribution of the property of conducting electricity can also be reduced to a conditional: if the cable received electrical power, it would transmit it. But imagine that the cable is connected to an informative tool (fink) that faithfully records if the cable is going to receive electricity and, if so, makes the cable instantly inert and unable to conduct electricity. In this case, the counterfactual conditional is not satisfied: if the cable received electrical power, it would not transmit it. Nevertheless, by hypothesis, the cable has this power. This means that meeting the conditional is not necessary to have the disposition in question. An inverse case, in which a reverse informant makes an inert cable capable of conducting electric current when the current itself is about to reach it, indicates that satisfying the conditional is not even sufficient to have the power in question.

In these cases, the stimulus, or something connected with the stimulus, causes an entity to lose or acquire the power in question at the very moment when the stimulus is about to activate the power. Instead of activating the powers of the entity, the stimulus

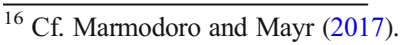


changes them. And conditional analysis comes up against great difficulties, because it denies that powers are genuine properties. As for masks, they act so that the stimuli do not involve a change in the entity considered in relation to the power. Their action is to block the manifestation of power through other causal factors. Consider the example of poison proposed by Molnar (2003: 93). The "reducing" conditional, which amounts to the attribution of the disposition, is: if the poison is ingested by an organism, the organism will die. One can however imagine that the poison's power to kill the organism when ingested might be blocked by the specific antidote, if taken in time. The conditional is thus falsified, although the entity (the poison) still has the power in question, i.e. the power to kill an organism if ingested.

Conditional analysis is thus called into question by these counterexamples. However, one could then try to reduce powers through a causal analysis, as follows: an entity is inclined to give a certain response to a certain stimulus if and only if the entity has properties that would bring that entity to give that answer if it received that stimulus. These properties obviously cannot be powers, but they must be categorical properties. The counterexamples of informants and masks, though, remain valid, even considering categorial properties. The critics of powers, though, did not give up and have proposed other versions of causal analysis, trying to save it from the aforementioned counterexamples. ${ }^{17}$ In any case, the great difficulties of reductive analyses have severely undermined the plausibility of hypotheticalism.

On the other hand, as regards nomism, the situation seems to be the following. ${ }^{18}$ According to nomism, the fundamental elements are the laws of nature, and both powers and counterfactual truths can be reduced to truths about the laws of nature. One law of nature says that whenever fire and icy water are in a certain spatial relationship (in general, when they are close), the ice melts. In this case it is the law that somehow gives the fire the power to melt the ice. The point is how this can happen. Three strategies can be identified in this respect. The first is the simplest. The law embodies the powers: any instantiation of fire has the power to melt ice. In this situation, the powers of the different entities can be deduced from the laws themselves. But in that way, the specific form of the law seems to be understood based on the understanding of the powers of the entity that the law describes. So, if the powers are not fundamental, the laws will have to look different.

The second strategy excludes powers from the laws of nature in order to overcome the previous objection. In this case, the law of nature simply states that the ice will melt whenever it meets fire. However, even if this objection is overcome, another one arises. In fact, it is unclear how the powers that manifest themselves can be deduced from the laws of nature, since the aim should be precisely to reduce powers to the latter. Finally, the third strategy adopts the Dretske-Tooley-Armstrong theory (Carroll 2016). In this interpretation, powers are not directly written into the laws of nature, thus preventing the first objection. To answer the second objection, the aforementioned theory introduces the so-called nomic necessitation, a special relationship that holds between two properties. In this case, there is a relationship of nomic necessitation that holds between the property of being fire in a specific spatial relationship with respect to ice and the property of being melting ice.

\footnotetext{
${ }^{17}$ Cf. Lewis (1997).

${ }^{18}$ Cf. Koons and Pickavance (2017); Boyd (2011).
} 
The problem with this interpretation of the laws of nature arises when one wonders whether the nomic necessitation relationship is an internal or an external one. If it is an internal relationship, the relationship has the character of necessity, which is positive, but leads directly back to powers as the actors of causal explanation. If, in fact, the intrinsic properties of fire matter, then we return to the first objection to the reductive perspective of the laws of nature. Instead, if the nomic necessitation relationship is external, then we must ask whether it is a necessary or contingent relationship. In both cases, it seems that there is no convincing explanation of why it is necessary or contingent, or at least proponents of the perspective of natural laws have not yet provided one. Ultimately, from the point of view of powerism, the laws of nature are simple descriptions of the powers that entities have. There is no need to postulate any further metaphysical necessities to reduce powers to properties of different kinds.

All this does not prove that powerism has the final word, but at least indicates that it is a metaphysical theory endowed with good explanatory capacity and theoretical parsimony, so that it can well compete with the other theories on the market.

\section{The metaphysics of powers}

In the light of the above, it appears that the self is also an entity that possesses some powers. According to the Aristotelian perspective of powers, every entity has a disposition to realize a certain behavior. If we consider the mental activity of the self, it is clear some mental powers do exist. In fact, the very ability of the self to instantiate mental events reveals that mental powers exist. We shall only refer to the mental powers of the self, stressing some principles that describe the relevant features of such mental powers. We can prima facie assume that the core principles of mental powers are the following:

$\mathrm{P} 1$ : For every $\mathrm{x}$, if $\mathrm{x}$ is a substance or a substantial entity, $\mathrm{x}$ necessarily has some powers.

It could be said that the powers of a substance can be seen as the properties of this substance. Every substance necessarily has some properties. For example, a physical substance can have the property of being burnt: for instance, I can burn a piece of paper. However, if we consider the self, our mental substance can experience a specific kind of mental states and can instantiate some mental events. In this way, the very concept of mental powers derives from the notion of mental substance. A fundamental power exists only if there is a fundamental entity that is the subject of that power. Thus, a power can be such if it is a power of a substance. The idea of substance is therefore pivotal to comprehend the idea of power.

P2: Mental powers are necessarily the causal properties of a mental substance.

If $\mathrm{P} 1$ is true, substances and powers are connected because a power represents the capacity to exhibit a change. In this way, a power is constructed as the possibility for a substance to change. We can attribute a power to a substance when a substance has a disposition to realize a certain behavior or when this substance can change its status. 
Consequently, we can consider mental powers as authentic causal properties of the subject because every time the subject instantiates an intentional object, they determine a change. This possibility of instantiation reveals the capacity of the self to realize some dispositional properties.

Let's suppose that $\mathrm{x}$, as a subject of consciousness, is the entity that conceives his mental states and that these mental states either can or cannot be conceived. Therefore, since these mental states might be intentionally described through some propositions, $x$ is a substantial entity that owns some properties. But $x$ also has the powers to realize or manifest a certain act, namely $x$ can determine the intentional object of their mental states. If I'm thinking of my kitchen, I am directing my mental state to an intentional object and this instantiation is the performance of a mental act. ${ }^{19}$ When a mental state is directed towards an intentional object and only to that object, a change has been determined, and so our self or substance deliberately changes its status. In this way, a causal relation is operative between the intentional state and the intentional object.

This relation is actively operated by the self who decides to direct its thought to something. So, my thinking of something is the actual and active realization of the active mental power of the substantial entity who corresponds to myself. By contrast, I might very well only be disposed to do something without actually doing something. The self can perform a certain mental act, but it can only be disposed to perform that act. For instance, an individual who is not familiar with logic or mathematics will probably never instantiate Skolem's results as an intentional object in their mind, but this doesn't mean that, if they decide to study this subject, they won't be able to perform that act in the future. So, we are all potentially disposed to direct our intentional states to an infinite number of intentional objects without actually doing it. The possibility for everyone to direct their thoughts to something in terms of the capacity of the self to instantiate an intentional object reveals the existence of the causal powers of the self as we conceive of them. Thus, if the self has some mental powers, these are causal powers and they are the causal properties of the self.

\section{P3: Mental powers are necessarily intrinsic.}

Mental powers belong to the essential nature of the subject. In fact, the subject can have experiences that cannot be described in a relational way. For instance, my experience of joy definitely derives from an intrinsic power: I am disposed to feel that kind of emotion, but such an experience is private and subjective, i.e. it belongs to myself. Our first-person perspective shows the existence of some intrinsic qualities of our subjective experience that cannot be accounted by a third-person perspective. In the last few decades scholars have proposed several thought experiments ${ }^{20}$ and counterfactual situations that show how phenomenal aspects cannot be explained in terms of the intentional aspects of mental states.

As regards the analysis of mental intentional aspects, Searle (1992) defended the existence of a sort of phenomenal intentionality. A similar claim was made by Strawson

\footnotetext{
${ }^{19}$ Strawson (1994) contends that our thoughts often happen abruptly in our minds without any conscious volition or "direction" on our part. However, this position seems largely focused on the nature of our introspection, not on the structure of our intentionality.

${ }^{20}$ Cf. Block (1990), Chalmers (1996), Shoemaker (1982) on the analysis of the intrinsic character of phenomenal aspects.
} 
(1994), who argued that our mental states are fundamentally phenomenal states. According to cognitive phenomenology, there is something it is like to think of a propositional content. It appears evident that there is a subjective manner to instantiate an intentional state. Every time I direct a mental state $x$ to an intentional object $y$, there is a what it is like to think of $y$. Obviously, this does not exclude the inter-subjective character of the information that is the content of $x$ : rather, this suggests that the intentional properties of $x$ lie in consciousness.

Our private awareness of beliefs and thoughts reveals the existence of an inescapable connection between phenomenology and mental intentionality. We can have experiences of thinking about something, experiences of understanding a sentence and experiences of all the propositional attitudes we use to perform certain mental acts. However, there are many philosophers who refute this thesis by denying that there exists this kind of intentional experience.

For instance, Chalmers (1996) argues that intentional properties are completely reducible to physical properties and lack of any intrinsic feature. According to Chalmers, the main aspects that characterize intentional states are only functional aspects and therefore any intentional system could be physically realized. So, an intentional system can be realized even if there is no consciousness. However, we are not saying that intentional states generally or by definition depend on phenomenal states or that, in order to individuate intentionality in whatever system, that system must be conscious. Intentionality is commonly defined as the capacity of a state or a thing to stand for something different, which can be an object, a property, a relation or a state of affairs. So, there is a kind of intentionality that can be reduced to extrinsic elements, such as the relations between functional states, inputs and outputs that we can find in a functional system.

However, there is not a single way in which we can describe intentionality. Let's consider the kind of intentionality exhibited by the human mind, which is deeply connected to consciousness. As a matter of fact, when at an instant $t$ I'm in an intentional state that will justify my intentional proposition that describes it, I'm also conscious of it. Chalmers accepts only one description of intentionality, namely the "functional intentionality", which must be distinguished from "phenomenal intentionality".

Horgan and Kriegel (2008) describe phenomenal intentionality as "a kind of intentionality that phenomenally conscious states exhibit, and moreover exhibit precisely in virtue of being phenomenally conscious states, that is, in virtue of their specific phenomenal character". The claim they make is that "there are mental states the instantiate properties whose nature is both phenomenal and intentional: the constitutive phenomenal character of such properties is intrinsically intentional". This intentionality individuates internally and is subjective since it presents its content to the subject.

We are focusing on this second sense, because the peculiar intentionality of the human mind doesn't manifest only functional aspects but is characterized by the fact that most mental activities happen in our consciousness. The intentional objects of our thoughts or beliefs lie in consciousness when I instantiate them at an instant $t$ and they are described by the propositions I intentionally utter. We are also conscious of a mental act when we are directing a mental state to an intentional object.

This is not to say that some operations or functions of our mind are not unconscious or that consciousness is a necessary prerequisite for any form of intentionality. But here we are not taking into account the mental functions of which we are not aware; instead, 
we are focusing on the specific kind of mental states that provide justification for one's intentional propositions. I'm totally conscious of these mental states because they constitute the internal condition of justification of the propositions I use to describe my mental domain. Hence, it appears that consciousness plays a fundamental role in determining the kind of experience we possess once we instantiate the mental states that support the evidence of our intentional propositions. For this reason, consciousness and intentionality are interlinked within our minds. The fact that there exist other kinds of mental acts we are not aware of doesn't rule out the fact that when we realize a mental activity that will be described by an intentional proposition we are also having an experience of that activity.

So, consciousness is really a prerequisite for a certain kind of instantiation of intentional mental states, otherwise we would not have access to the intrinsic property that qualifies the intentional mental states we instantiate at an instant $t$ and that support the evidence of our intentional propositions. The fact that when we are thinking about something, at a present instant $t$ and being fully aware of it, we are also providing justification for intentional propositions that appear evident to us proves that we can't consider mental intentionality in the sense of "functional intentionality". "Functional intentionality" is not what characterizes all mental states and it is not a constitutive feature of the mental domain, because the intentional states that are conditions of justifications for evident intentional propositions are phenomenal intentional states.

Kriegel $(2003,2011)$ claims that genuine intentionality needs a subjective component, such that representations can in principle represent what they do to someone. Only conscious representations are capable to represent to their subject in and of themselves and not purely derivatively. As phenomenal intentionality is non-derivative, phenomenally conscious states have a different intentionality from non-conscious states, whose intentionality is similar with that of language and other conventional systems of representations (cf. Loar 2003; Horgan 2013; Horgan and Graham 2012).

Thus, we should not apply intentional categories to behavioral dispositions and remove them from experience. Mental intentionality is not only aimed at providing a perspective to explain behavior: it is also realized in our subjective experience of mental states. Experiences like thinking about something or wishing that something may happen suggest that we cannot define human intentionality only based on behavioral dispositions, but we need to extend it to subjective and private experiences. The mental capacity or mental property of a state of being about something is not accountable only through causal connections between sensorial inputs and behavioral outputs: within the cases regarding mental states that support the evidence of some intentional propositions, it is connected to consciousness. Consequently, the mental powers we manifest to instantiate some intentional objects can be considered as "intrinsic", as we are taking into account those conscious mental states that make evident the propositions about our mental domain. Thus: if the self has a private awareness of some mental intentional states and is able to causally instantiate these states through its causal powers (according to P1 and P2), then its mental powers are intrinsic.

P4: Mental powers are necessarily irreducible.

If $\mathrm{P} 3$ is true, then the mental powers of the self are not reducible to any physical property because of their intrinsic nature. Every physical property has a relational 
character, namely it can be analyzed through a third-person perspective. A relational property is based on a relation between structures and functions and is described on a functional level. The features of a physical perspective are necessarily public and inter-subjective. However, our mental powers cannot be described in such a way, as they are manifested and realized in each individual's private space of subjectivity. Since mental powers are intrinsic, they don't share any common property with physical items. For example, I can understand my friend's intention to stay awake in order to watch the Superbowl, but the fundamental condition of him possessing a mental state that represents his desire to watch the Superbowl is impenetrable to me. The experience of my own thoughts will remain confined in my subjective world, even though I'm able to communicate the contents of my thoughts to another individual. Thus, mental powers are not naturalizable and are not reducible to physical properties.

These four principles describe the self's capacity to change in order for it to produce a causation by itself. All these principles formalize the connection between the substantial entity and its causal properties. The possibility of thinking and experiencing, i.e. the possibility for the self to have consciousness of something, is given by the existence of irreducible mental powers. Moreover, mental powers allow the self to actively interact with the world (Giorgi and Lavazza 2018).

The existence of mental powers is also extensively supported by the prima facie experience of the self as a substantial entity and by the analysis of the evident propositions that describe our mental states. Self-consciousness and evident propositions reveal the existence of a self, described as an entity characterized by an individual essence. Consequently, if the self is conceived of as a substance, we are able to analyze the properties of this substance. Mental powers are the self's causal properties, namely the causal properties of this specific substance, conceived of as an individual entity with an essential character. Once we have accepted that the self is a substance, we can define this substance's causal properties. This means that mental powers are automatically derived from the very nature of the self, and the existence of mental powers descends from the very notion of substance. If the self is a substantial entity, it is also able to perceive and causally interact with the world in the way we described. So, in this sense, if the self exists, its powers are true by default since their nature is part of the substantial nature of the self. Mental powers exhibit the causal interaction of the self and can be defined as the genuine causal properties of this substantial entity. In addition, the very possibility of having subjective experiences reveals the presence of the powers of the subject.

\section{Conclusion}

We have identified some intentional propositions that are evident for us because they describe our mental states. Indeed, we know that these propositions are evident because they are internally justified by conscious states to which the subject has introspective access. These evident propositions entail the existence of a specific property that qualifies the nature of the self as a substance, i.e. an entity necessarily identical to itself. This means that through the analysis of these evident propositions 
we are able to individuate an essential property. This property defines and distinguishes every individual self from the others, and so it defines our individual essence: that is, each of us exists as an individual substance with a specific essential nature. The essential nature of every substance is based on the aspects of unity, indivisibility and simplicity.

We have also analyzed the phenomenological data we have about our internal intuition of the self as a substantial entity. This intuition is conceivable as a sort of self-consciousness, namely an internal awareness of the self as a simple thing or a thing in itself. Indeed, when we internally perceive this thing, we always grasp it totally and in its entirety. We grasp it directly and immediately, not in a partial or composed way but always as an entity perceivable in its totality. So, even our phenomenological perception of the self allows us to recognize its essential nature and its existence as a substantial entity.

Once we have demonstrated the existence of a substance that corresponds to the self, we have proceeded to identify the causal properties of this substance, namely its mental powers. These mental powers of the self correspond to the pure intentional acts that are realized when we instantiate thoughts in our mental domain. This instantiation of thoughts is explained by considering the voluntary and conscious direction of our intentional states towards any intentional object. Finally, we have have defended the idea that these mental powers are intrinsic and irreducible because they possess a phenomenal character which makes them non-naturalizable and distinct from any physical property.

The property that specifies the individual essence is not a causal property, because it qualifies each individual subject as such. We couldn't demonstrate the existence of mental powers without considering the self and we couldn't simply show the reality of the substance through its causal powers. The reason for this is that mental powers necessarily belong to something and should be attributed to an entity. So, before proceeding to the analysis of causal powers, we need to demonstrate that there is a self and that this self is not just a functional self or a narrative self, but an entity that exists as always identical to itself by possessing an individual essence.

All that said, the burden of proof lies with the positions that deny the existence of the self as a substance. In order to be skeptical about the existence of mental powers, critics of such a thesis should reject the existence of the self as a substantial entity, but this is not an easy task, for the reasons explained above. Once one decides to accept the simplicity of the ontology of the self and its essential nature, it seems like one cannot avoid accepting the existence of mental powers as well.

In this way we have shown how a classic problem of philosophy of mind can be addressed in an original way by a metaphysical approach involving powers. This approach is also helpful for science in that it cannot easily accommodate the self and the related powers in its ontology. In this vein, a philosophical model like ours might allow science to consider the self as an actual entity in a logically consistent view of reality. ${ }^{21}$

Funding Open access funding provided by Università degli Studi di Pavia within the CRUI-CARE Agreement.

\footnotetext{
${ }^{21}$ The authors thank two anonymous reviewers for their very helpful comments to a precedent version of the paper.
} 


\section{Compliance with ethical standards}

Disclosure of potential conflicts of interest The authors declare they do not have any conflicts of interest.

\section{Research involving human participants and/or animals Not applicable.}

\section{Informed consent Not applicable.}

Open Access This article is licensed under a Creative Commons Attribution 4.0 International License, which permits use, sharing, adaptation, distribution and reproduction in any medium or format, as long as you give appropriate credit to the original author(s) and the source, provide a link to the Creative Commons licence, and indicate if changes were made. The images or other third party material in this article are included in the article's Creative Commons licence, unless indicated otherwise in a credit line to the material. If material is not included in the article's Creative Commons licence and your intended use is not permitted by statutory regulation or exceeds the permitted use, you will need to obtain permission directly from the copyright holder. To view a copy of this licence, visit http://creativecommons.org/licenses/by/4.0/.

\section{References}

Baars, B. (2006). Global workspace theory of consciousness: Toward a cognitive neuroscience of human experience? In S. Laureys (Ed.), The boundaries of consciousness. Amsterdam: Elsevier.

Block, N. (1990). Inverted earth. Philosophical Perspectives, 4, 53-79.

Boyd, D. (2011) Powerism. "Ex nihilo", 1, pp. 44-49. https://repositories.lib.utexas.edu/bitstream/handle/ 2152/13600/2011_ExNihilo.pdf?sequence=2\&isAllowed=y.

Carroll, J. W. (2016) Laws of nature. The Stanford Encyclopedia of Philosophy, Edward N. Zalta (ed.). https:// plato.stanford.edu/archives/fall2016/entries/laws-of-nature/.

Carruthers, P. (2017). The illusion of conscious thought. Journal of Consciousness Studies, 24(9-10), 228252.

Chalmers, D. (1996). The conscious mind. New York: Oxford University Press.

Chisholm, R. M. (1976). Person and object. La Salle: Open Court Publishing.

Chisholm, R. M. (1989). On metaphysics. Minneapolis: University of Minnesota Press.

Christopher, J., \& Marmodoro, A. (2017). Structural powers and the Homeodynamic Unity of organisms. In W. M. R. Simpson, R. C. Koons, \& N. J. Teh (Eds.), Neo-Aristotelian Perspectives on Contemporary Science. New York: Routledge.

Churchland, P. M. (1981). Eliminative materialism and the propositional attitudes. Journal of Philosophy, 78, 67-90.

Crick, F., \& Koch, C. (2003). A framework for consciousness. Nature Neuroscience, 6(2), 119-126.

Crick, F., \& Koch, C. (2005). What is the function of the Claustrum? Philosophical Transactions of the Royal Society, 360(1458), 1271-1279.

Dennett, D. C. (1971). Intentional systems. Journal of Philosophy, 68, 87-106.

Dennett, D. C. (1987). The intentional stance. Cambridge: The MIT Press.

Dennett, D. C. (1991). Consciousness explained. Boston: Little, Brown and Co.

Giorgi, R., \& Lavazza, A. (2018). Mental causation. APhEx, 17. www.aphex.it.

Graziano, M. (2013). Consciousness and the social brain. Oxford: Oxford University Press.

Harman, G. (1990). The intrinsic quality of experience. Philosophical Perspectives, 4, 31-52.

Horgan, T. (2013). Original intentionality is phenomenal intentionality. The Monist, 96, 232-251.

Horgan, T., \& Graham, G. (2012). Phenomenal intentionality and content determinacy. In R. Schantz (Ed.), Prospects for meaning. Amsterdam: De Gruyter.

Horgan, T., \& Kriegel, U. (2008). Phenomenal intentionality meets the extended mind. The Monist, 91, 353380.

Kind, A. (2015). Persons and personal identity. Malden: Polity Press.

Koch, C., Massimini, M., Boly, M., \& Tononi, G. (2016). Neural correlates of consciousness: Progress and problems. Nature Review Neuroscience, 17, 307-321.

Koons, R. C., \& Pickavance, T. H. (2015). Metaphysics. The fundamentals. Malden: Wiley Blackwell. 
Koons, R. C., \& Pickavance, T. H. (2017). The Atlas of Reality. A Comprehensive Guide to Metaphysics. Malden: Wiley Blackwell.

Kriegel, U. (2003). Is intentionality dependent upon consciousness? Philosophical Studies, 116(3), $271-307$.

Kriegel, U. (2011). The sources of intentionality. Oxford: Oxford University Press.

Lewis, D. (1997). Finkish dispositions. The Philosophical Quarterly, 47, 143-158.

Loar, B. (2003). Phenomenal intentionality as the basis of mental content. In M. Hahn \& B. Ramberg (Eds.), Reflections and replies: Essays on the philosophy of Tyler Burge. Cambridge: The MIT Press.

Marmodoro, A. (2007). The Union of cause and effect in Aristotle: Physics III 3. Oxford Studies in Ancient Philosophy, 32, 205-232.

Marmodoro, A. (2009). Do powers need powers to make them powerful? From Pandispositionalism to Aristotle. History of Philosophy Quarterly, 26(4), 337-352.

Marmodoro, A. (2010). The Metaphysics of Powers: Their Grounding and Their Manifestations. New York: Routledge.

Marmodoro, A., \& Mayr, E. (2017). Breve introduzione alla metafisica. Roma: Carocci.

Martin, C. B. (1994). Dispositions and conditionals. The Philosophical Quarterly, 44, 1-8.

Meixner, U. (2004). The two sides of being: A reassessment of psychophysical dualism. Paderborn: Mentis Verlag.

Molnar, G. (2003). Powers: A study in metaphysics. Oxford: Oxford University Press.

Mumford, S., \& Anjum, R. L. (2011). Getting causes from powers. New York: Oxford University Press.

Parfit, D. (1984). Reasons and persons. Oxford: Clarendon Press.

Ryle, G. (1949). The concept of mind. London: Hutchinson and Co..

Searle, J. (1992). The rediscovery of the mind. Cambridge: The MIT Press.

Shoemaker, S. (1982). The inverted Spectrum. Journal of Philosophy, 79, 357-381.

Shoemaker, S., \& Swinburne, R. (1984). Personal identity. Oxford: Basil Blackwell.

Spinoza, B. (1677) Ethics, in The Collected Works of Spinoza. Edwin Curley (ed. and trans.), Princeton: Princeton University Press.

Strawson, G. (1994). Mental reality. Cambridge: The MIT Press.

Tononi, G. (2008). Consciousness as integrated information: A provisional manifesto. Biological Bulletin, $215(3), 216-242$.

Tononi, G., \& Koch, C. (2015). Consciousness: Here, there and everywhere? Philosophical Transactions of Royal Society of London B: Biological Sciences., 370, 20140167.

Tononi, G., Boly, M., Massimini, M., \& Koch, C. (2016). Integrated information theory: From consciousness to its physical substrate. Nature Review Neuroscience, 17, 450-461.

Wuerth, J. (2014). Kant on mind, action, and ethics. New York: Oxford University Press.

Publisher's note Springer Nature remains neutral with regard to jurisdictional claims in published maps and institutional affiliations.

\section{Affiliations}

\section{Rodolfo Giorgi ${ }^{1} \cdot$ Andrea Lavazza ${ }^{2,3}$}

Rodolfo Giorgi

rodolfo.giorgi@ libero.it

1 Dipartimento di civiltà e forme del sapere, Università di Pisa, via Paoli, 15, Pisa, Italy

2 Centro universitario internazionale, Via Garbasso, 42, Arezzo, Italy

3 Università degli Studi di Pavia, Pavia, Italy 